\title{
Cuestionando el tratamiento tributario del Goodwill
}

El actual tratamiento tributario del Goodwill y el Badwill produce desigualdad tributaria. En el caso del Goodwill, esta se explica por la imposibilidad de que el contribuyente reconozca pérdidas efectivas surgidas en un proceso de fusión, sino hasta que la organización que las registra se disuelva o lleve a cabo el término de su giro empresarial. En el caso del Badwill, esta surge de la tributación de utilidades que eventualmente ya tributaron en sus orígenes. Estas situaciones podrían incentivar al contribuyente a buscar alternativas para evitar una potencial doble tributación interna o a reconocer, justificadamente y en el corto plazo, las pérdidas generadas en un determinado proceso de fusión de sociedades. Una alternativa para contrarrestar estos efectos es, por medio de una modificación legal, reconocer el genuino derecho a utilizar las pérdidas y buscar una metodología que permita distinguir utilidades que ya tributaron en sus organizaciones de origen.

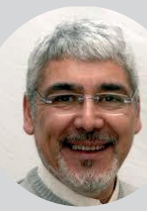

René González Madrid MAGÍSTER EN PLANIFICACIÓN Y GESTIÓN TRIBUTARIA, UNIVERSIDAD DE SANTIAGO DE CHILE PROFESOR DE CONTABILIDAD Y AUDITORÍA, UNIVERSIDAD ALBERTO HURTADO

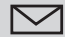

rgonzalez@uahurtado.cl

\section{Introducción}

Cada cierto tiempo y en distintos ámbitos aparecen nuevos términos y originales conceptos que se vuelven moda. En el ámbito de los negocios, en el año 2016 el "Goodwill Tributario" explicaba la fuerte alza en los resultados financieros de dos importantes AFPs, incrementando una de ellas en más de un $149 \%$ sus utilidades en el ejercicio 2015, respecto del año 2014. Pero ¿qué es el "Goodwill Tributario"?

Entre los distintos tipos de reorganización empresarial existentes, encontramos la fusión de sociedades, entre las que se destacan la fusión por incorporación o fusión "propia" y la fusión "impropia", que consiste en la reunión del 100\% de las acciones o derechos sociales de una sociedad que resulta absorbida en un solo propietario (Ley 18.046, 1974). En este caso, sólo por el ministerio de la ley se produce una absorción por fusión de los activos y pasivos. Es decir, por la compra del total del patrimonio se absorben los bienes y obligaciones de la sociedad absorbida. Así, la fusión es una consecuencia y no un hecho jurídico expreso, sin perjuicio de que la verdadera motivación de la administración es la unión entre empresas (Pinto Perry, 2006). Producto de este tipo de reorganizaciones pueden surgir diferencias entre el valor de las inversiones en la sociedad absorbente y el valor patrimonial de la absorbida, diferencia conocida en el ámbito impositivo como Goodwill o Badwill Tributario. Específicamente, estos anglicismos corresponden a la diferencia que se produce en un proceso de fusión de sociedades, entre el precio de adquisición ${ }^{1}$ de las acciones 


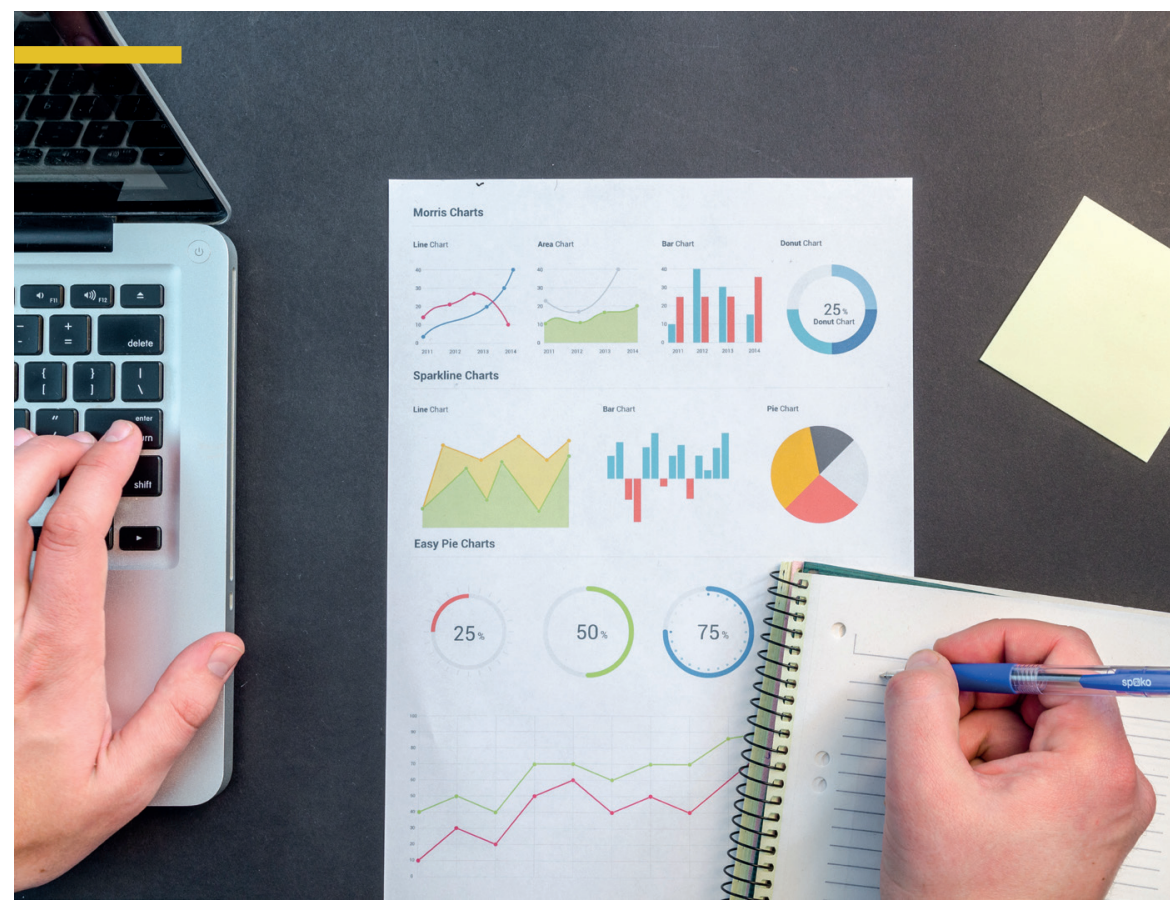

o derechos sociales registrados en los libros de una sociedad absorbente o matriz, y el patrimonio o capital propio tributario ${ }^{2}$ de la sociedad absorbida que se incorporan a la matriz, al momento de su adquisición. Si el precio de adquisición de los referidos títulos es superior al capital propio tributario de la sociedad absorbida, se genera una pérdida o menor valor para la sociedad absorbente y estaremos en presencia de un Goodwill tributario. En caso contrario, al generarse una ganancia o mayor valor estaríamos hablando de un Badwill tributario.

En la doctrina del Derecho Comercial, el término Goodwill está asociado al prestigio de una organización o la reputación de una determinada marca de propiedad de una empresa que, al momento de ser valorizada, puede tener un importe superior al que representa su valor patrimonial en la contabilidad. Por el contrario, el concepto del Badwill representa una mala reputación, es decir, una valorización en el mercado inferior a lo que figura en sus registros financieros (Flores y Vergara, 2014).
Contablemente, estos conceptos también plusvalías pendientes de realización de una empresa, respecto de la valorización de los activos y pasivos de una organización. Dicho lo anterior, si la empresa valorizada es absorbida en un proceso de reorganización, la buena o mala reputación se diluye en este proceso, generándose una pérdida si la reputación es buena o una ganancia si su mala reputación desaparece en esta instancia de etapa reorganizacional.

\section{Evolución legal de la diferencia}

Hasta el año 2012, Goodwill y Badwill se normaban -y no con poca desprolijidad - a través de jurisprudencia administrativa, vale decir, con oficios y circulares emitidos por el Servicio de Impuestos Internos (SII). En ese año, a través de la Ley 20.630 se corrigió y perfeccionó el tratamiento del Goodwill, incorporándose su tratamiento en el artículo 31, Nº de la Ley sobre Impuesto a la Renta, y son considerados en la valorización de

\section{C( el Goodwill tributario representa el menor valor} para la empresa absorbente en una inversión realizada en acciones de la sociedad absorbida respecto al capital propio tributario de la misma

el Badwill, en el artículo 15 del mismo cuerpo legal. La Reforma Tributaria establecida por la Ley 20.780 del año 2014, limitó la amortización o castigo del reconocimiento de la pérdida surgida en el Goodwill, hasta que la sociedad que registra el intangible se disuelva o concluya sus actividades, permitiendo a empresas que al 31 de diciembre de 2014 ya se encontraban en un proceso de reorganización, acceder a la norma anterior, siempre que informaran a través de una declaración jurada de tal situación además que el proceso de reestructuración estuviera concluido a diciembre de 2016 .

Por otro lado, la incorporación en la norma aludida del concepto "valor corriente en plaza", que limita la distribución del mayor o menor valor entre los activos no monetarios ${ }^{4}$ provenientes de la sociedad absorbida, es un verdadero acierto del legislador, por cuanto hasta antes de su implementación existía la posibilidad de que al aplicar las antiguas disposiciones, podían surgir activos no monetarios negativos - en el caso del

(2) Determinado por los contribuyentes sujetos al régimen de renta efectiva según contabilidad

(3) Inciso segundo, artículo 15 e inciso tercero, $N^{\circ} 9$, artículo 31; ambos de la LIR

(4) Activos no monetarios son aquellos que se protegen del efecto inflacionario de nuestra economía, ya sea por su naturaleza, o bien, por alguna cláusula de reajustabilidad que posea (por ejemplo: deudores reajustables, maquinarias, inmuebles, existencias, acciones, intangibles, etc.). 
Badwill - o permitir la adquisición presurosa de activos de fácil liquidación por la sociedad que desaparece, para así - elusivamente - realizar la pérdida en el cortísimo plazo.

Pero la norma del "valor corriente en plaza" no está exenta de complejidades. Una de las dificultades más importantes es poder encontrar mercados para tipos particulares de activos no monetarios como, por ejemplo, plantaciones frutales en pleno proceso reproductivo (activo biológico) o primores en etapa de crecimiento (producto agrícola).

\section{Tratamiento tributario del Goodwill}

El tratamiento tributario vigente en esta materia establece que el Goodwill tributario se debe distribuir proporcionalmente en cada uno de los activos no monetarios recibidos desde la sociedad absorbida con motivo de la fusión y que vienen a reemplazar el valor de su inversión. Es decir, la diferencia negativa sólo se asigna a los activos no monetarios provenientes de la sociedad absorbida y siempre que el costo tributario de los activos según sus registros sea inferior al valor corriente en plaza que ellos tengan, aumentando su valor tributario con tope de dicho monto.

El aumento del valor de los activos no monetarios hasta su valor corriente en plaza constituirá su nuevo costo tributario. Ello permitirá reconocer como pérdida la parte del Goodwill al momento de la venta, amortización, depreciación o liquidación del respectivo recurso. A continuación, se presentan breves ejemplos del señalado tratamiento.
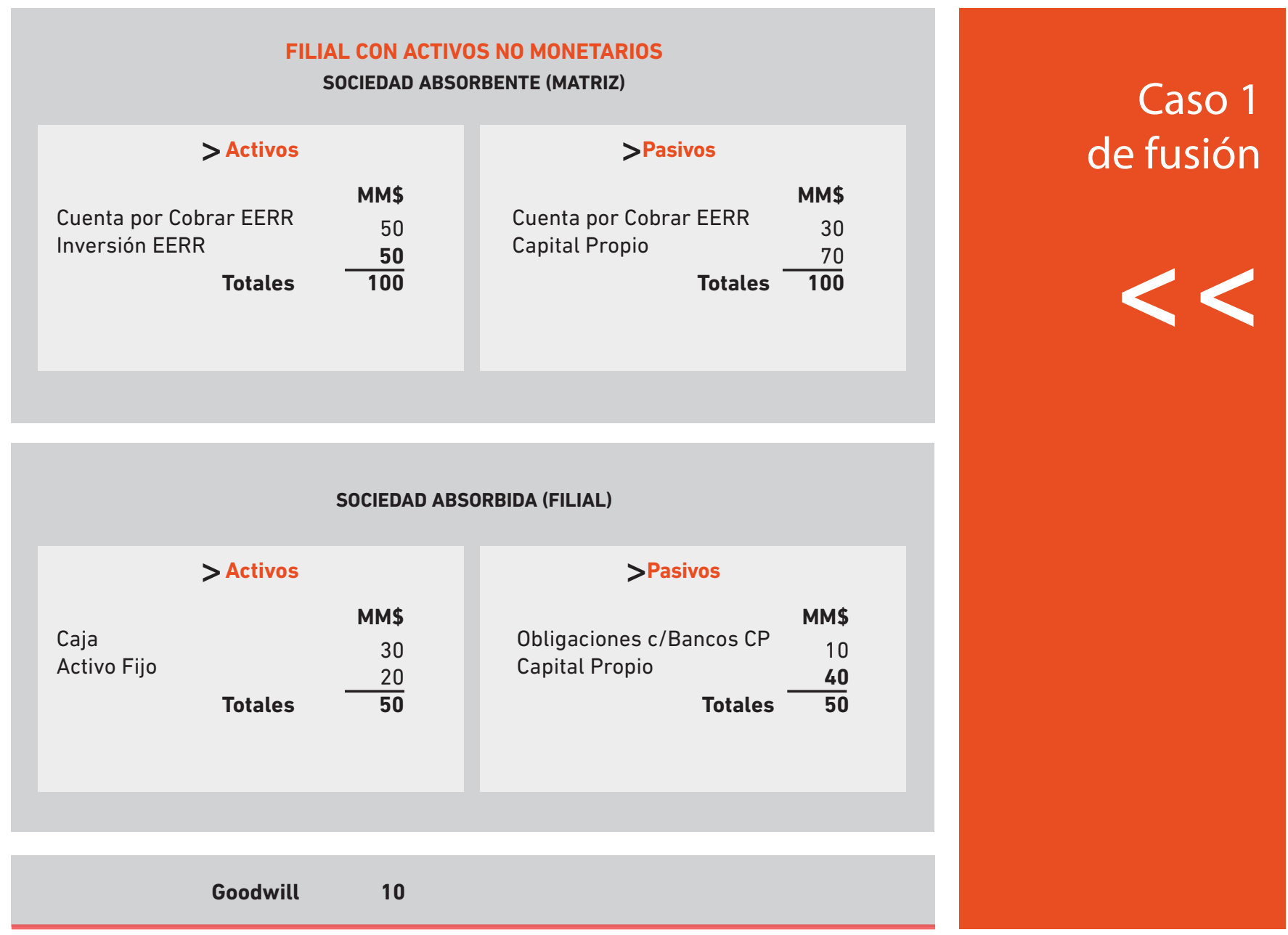

El caso 1 nos presenta un Goodwill Tributario de 10 unidades monetarias, debido a que el valor de la inversión en empresas relacionadas (EERR) en la sociedad absorbente alcanza la suma de 50 y el capital propio tributario que se integrará desde la sociedad absorbida solo alcanza a la suma de 40. Como la sociedad filial cuenta con activos no monetarios, esta diferencia incrementará el valor del activo (activo fijo), hasta su valor corriente en plaza, estimado para este caso en 30 unidades monetarias. Con estos antecedentes, la fusión impropia quedaría de la siguiente manera: 


\begin{tabular}{|c|c|}
\hline \multicolumn{2}{|l|}{ >Activos } \\
\hline & MM\$ \\
\hline Caja & 30 \\
\hline $\begin{array}{l}\text { Cuenta por Cobrar EERR } \\
\text { Activo Fijo }\end{array}$ & 50 \\
\hline & 30 \\
\hline Totales & 110 \\
\hline
\end{tabular}

\section{Pasivos}

Obligaciones c/Bancos CP Cuentas por Pagar EERR

MM\$

10

30

Totales $\quad \frac{70}{110}$

El nuevo valor tributario del activo fijo originalmente asentado en 20 - quedará registrado en 30 unidades monetarias, valor que deberá depreciarse y a través de esta amortización, se reconocerá la pérdida tributaria generada en la fusión.

Si el valor corriente en plaza del activo fijo hubiese sido, por ejemplo 40, el caso anterior no habría tenido variación, ya que la diferencia de 20 [40 - 20], habría incorporado el Goodwill de 10. En cambio, si el valor corriente en plaza hubiese sido 5, sólo esta cantidad del Goodwill se habría imputado al valor del activo fijo (quedando valorizado en
25). Las otras 5 unidades monetarias habrían generado un cargo diferido o activo tributario intangible de 5, considerado para efectos impositivos como una inversión efectiva realizada por la sociedad absorbente y, por tanto, parte integrante del capital propio tributario de la sociedad absorbente.

El valor del patrimonio de la sociedad absorbente no se modifica. No así el activo fijo, que, de un valor de 20, queda registrado como valor tributario de 30. La pérdida de 10 generada en la fusión se irá reconociendo en los resultados de la sociedad matriz a través de la mayor depreciación del activo o una vez que se produzca su venta, baja o liquidación.

La parte del Goodwill que no pudiera ser distribuida - producto de que no existen activos no monetarios o estos están valorizados en un monto superior al valor corriente en plaza, constituirá un gasto diferido o activo intangible para la sociedad absorbente, cargo diferido o derecho que no se puede amortizar y que formará parte de su patrimonio tributario, quedando sujeto a las normas de corrección monetaria establecidas en el artículo 41 de la LIR.
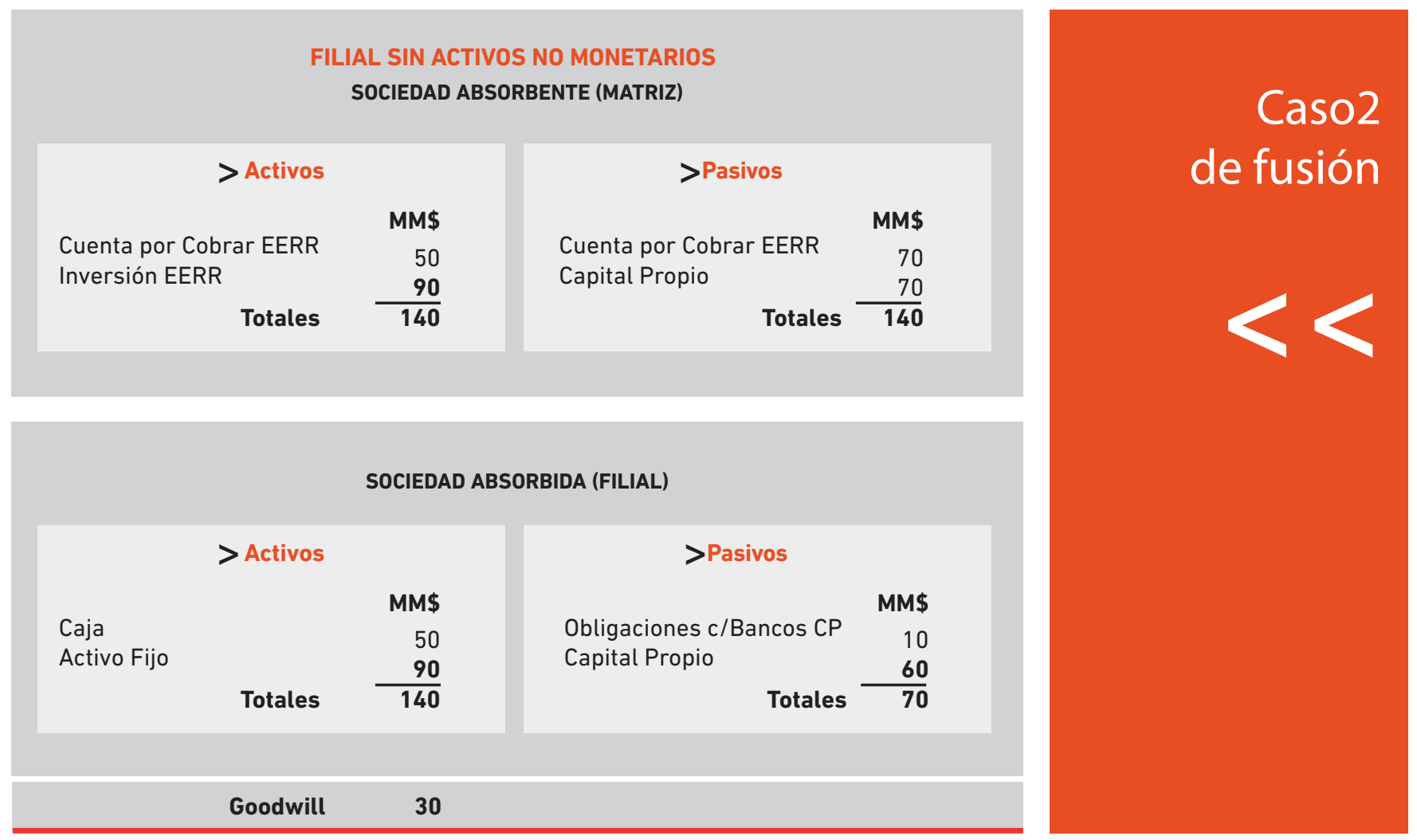

SOCIEDAD ABSORBIDA (FILIAL)

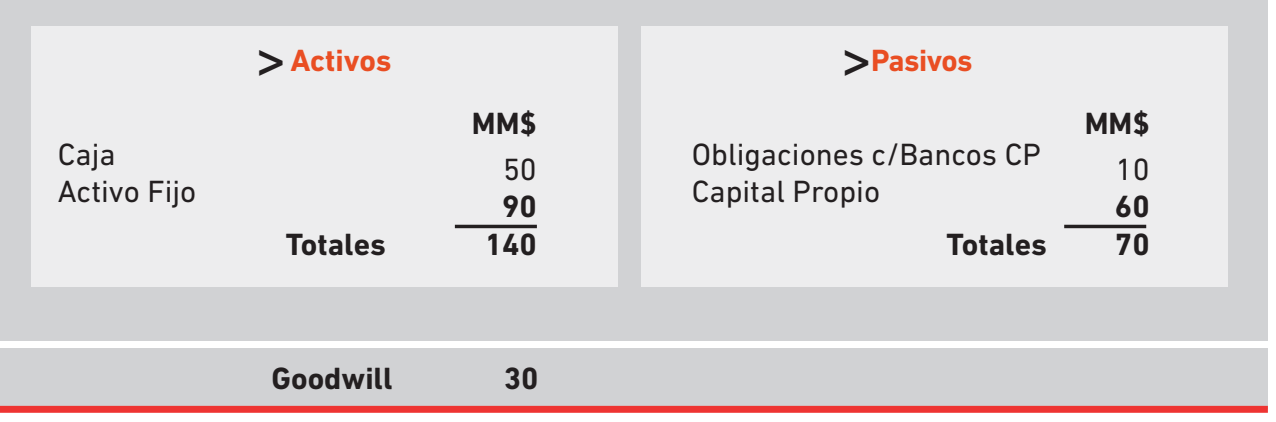


En este caso se genera un Goodwill Tributario de 30 unidades monetarias, debido a que el valor de la inversión en la sociedad absorbente alcanza la suma de 90 y el capital propio tributario que se integrará desde la sociedad absorbida solo alcanza a la suma de 60. Como la sociedad filial no registra activos no monetarios, esta diferencia constituirá un activo intangible de 30 . Con estos antecedentes, la fusión quedaría de la siguiente manera:

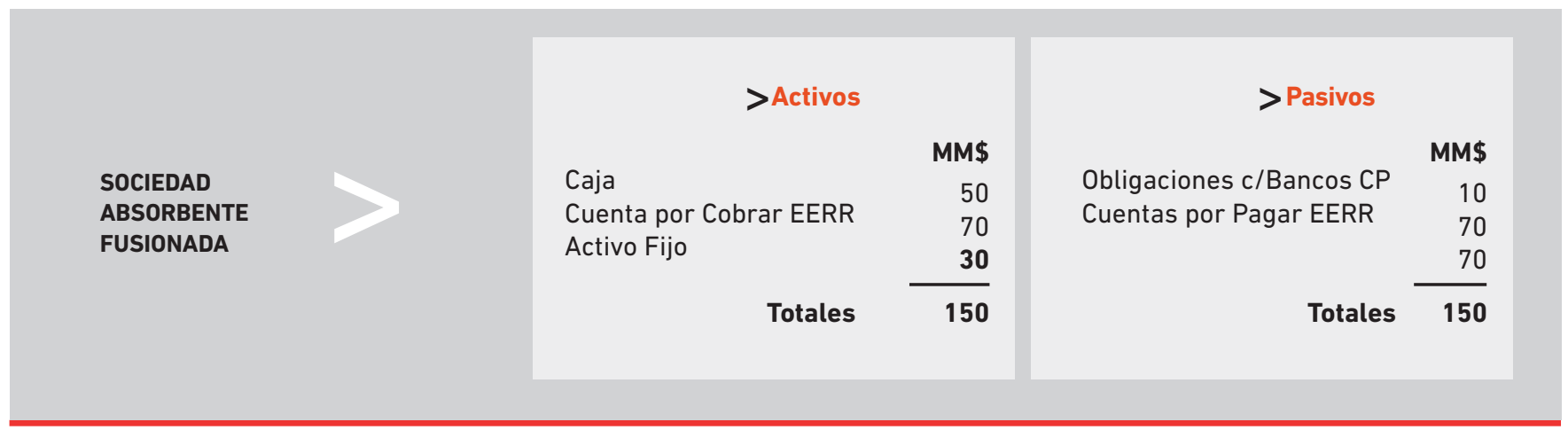

Tratamiento del Goodwill como activo intangible después de la reforma de 2014

Hasta la última gran reforma tributaria, la parte del Goodwill o menor valor que no podía distribuirse en activos no monetarios, se controlaba como un cargo diferido o activo intangible que podía ser amortizado en diez años como una pérdida tributaria (ley $\left.\mathrm{N}^{\circ} 20.780,2014\right)$. Producto del reconocimiento de esta pérdida, el contribuyente podía rebajarla de sus utilidades afectas a Impuesto de Primera Categoría durante ese período de tiempo, lo que se traducía en un menor pago de impuestos empresariales. La situación tributaria de reconocimiento de futuras pérdidas generaba a su vez el desarrollo de activos y utilidades financieras producto de los impuestos diferidos subyacentes, lo que permitía mejorar sustancialmente la estructura financiera de la organización.

A contar del $1^{\circ}$ de enero de 2015, el activo intangible surgido del Goodwill ya no se puede amortizar en un período de tiempo determinado, sino que sólo podrá ser castigado o amortizado al momento de la disolución de la sociedad, o bien, al término de giro de la misma.

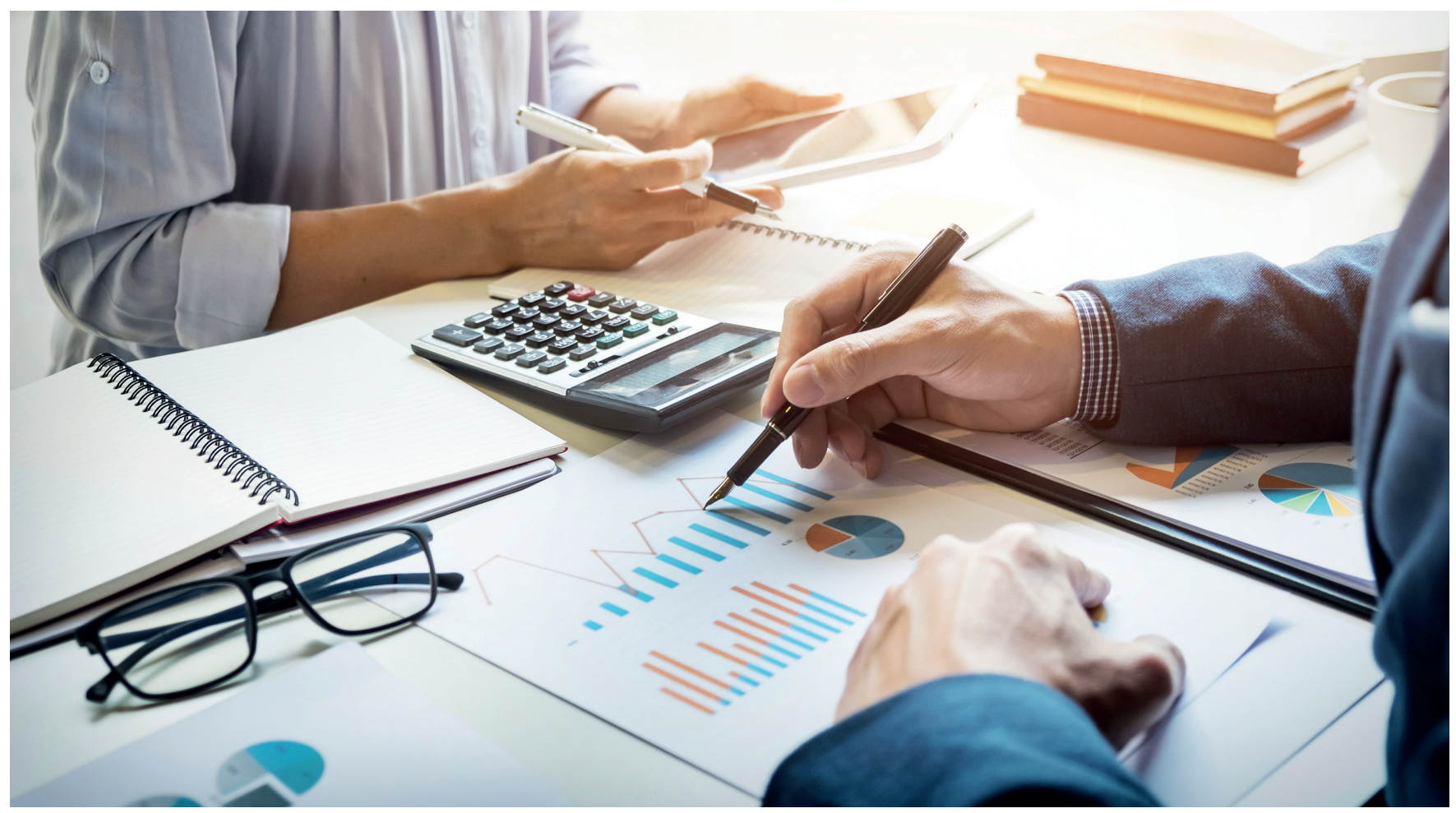




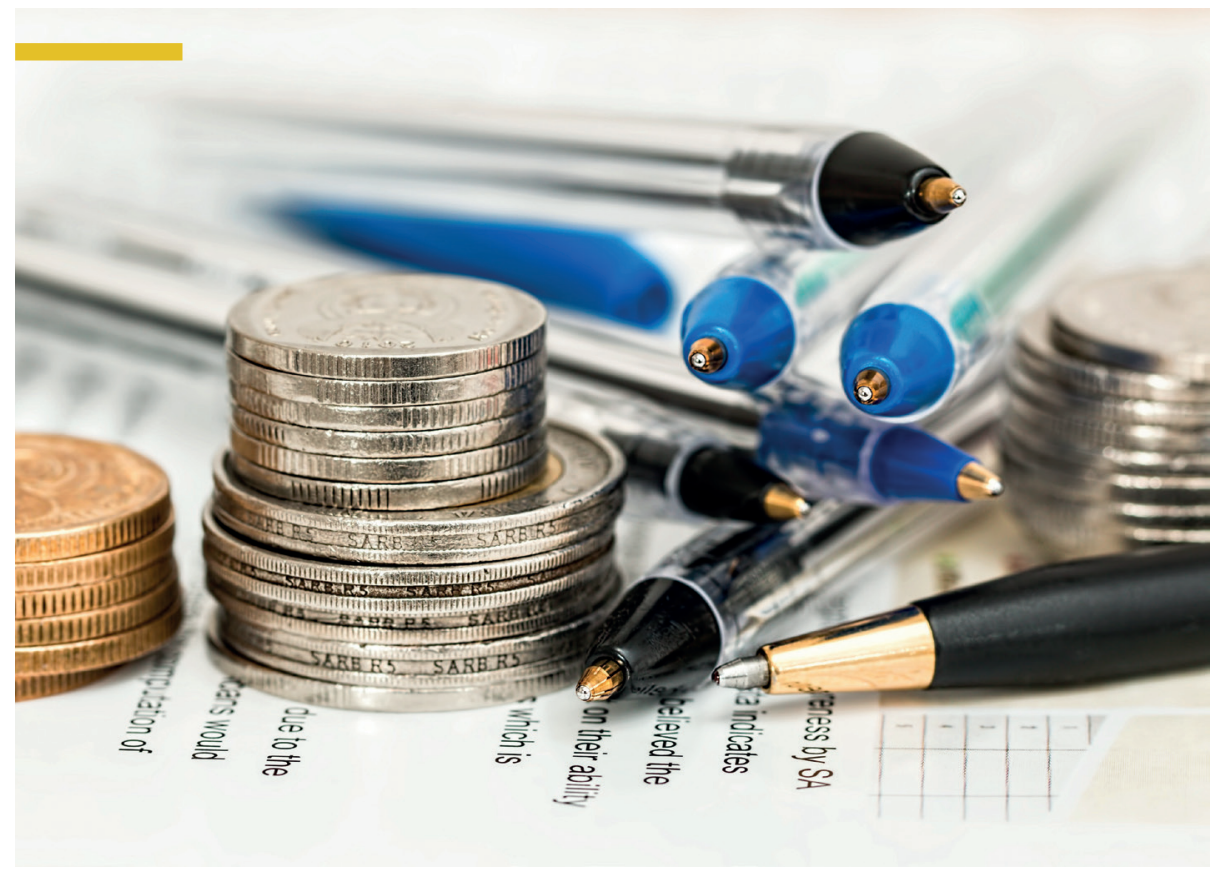

\section{《6 La normativa actual incentiva la elusión tributaria"}

\section{Cuestionamientos al actual tratamiento tributario del Goodwill}

La merma o detrimento natural en el patrimonio de cualquier organización son las pérdidas generadas por el negocio. Las normas tributarias reconocen el legítimo derecho del contribuyente de utilizar estas mermas surgidas en un ejercicio, como gastos necesarios para producir la renta en ejercicios posteriores.

Como se ha señalado, el Goodwill tributario representa la pérdida o menor valor para la empresa absorbente en una inversión realizada en acciones o derechos sociales de una sociedad que resulta absorbida y el valor del capital propio tributario de la misma, cuando éste se incorpora en la absorbente. En este contexto, ¿por qué en una situación de fusión sustentada en una legítima razón de negocios, la continuadora legal de la sociedad absorbida no puede utilizar estas pérdidas sino hasta que la sociedad se liquide o termine su giro?
Esta decisión de postergar el derecho de uso de las pérdidas podría constituir una inequitativa medida pro fisco de parte del legislador, provocando una sensación de injusticia tributaria en el contribuyente, al forzarlo esperar hasta la liquidación de la organización para poder utilizar las pérdidas. Entonces surgen los siguientes cuestionamientos: ¿dónde queda en nuestra actividad el principio fundamental de empresa en marcha ${ }^{5}$ ?. Además, innumerables empresas concluyen sus operaciones motivadas por sus enormes pérdidas surgidas en el desarrollo de su gestión, ¿de qué sirve entonces incrementar estos menoscabos con la amortización del Goodwill en esta instancia?

La aplicación de la norma así establecida, podría motivar al contribuyente buscar alternativas de planificación que pueden deslindar con la elusión tributaria, como por ejemplo, eliminar en la sociedad absorbida - antes de la fusión - todos los activos no monetarios de vida útil extensa, para concentrar la distribución del Goodwill en aquellos bienes que se liquidarán en el corto plazo o forzar una nueva fusión con tal de liquidar la sociedad que detenta el gasto diferido y utilizar así la pérdida.

Lo anterior, aun considerando la compleja implementación de las nuevas normas tributarias anti elusión contempladas en el Código Tributario y que - según entendidos - es de difícil aplicabilidad ${ }^{6}$.

Una sencilla modificación tributaria del tratamiento vigente, por ejemplo, volver al procedimiento utilizado con anterioridad a la reforma de 2014, podría permitir eliminar la controversia planteada anteriormente, es decir, permitir la amortización periódica de los cargos diferidos originados en un Goodwill.

\section{Conclusiones}

Con las últimas reformas tributarias queda de manifiesto la potestad del Estado en materia impositiva, permitiendo establecer beneficios en favor del fisco que pueden ir en desmedro de un

(5) Postulado básico de la IFRS.

(6) Opinión, entre otros expertos, del ex director del Servicio de Impuestos Internos, Sr. Ricardo Escobar (El Mercurio, 03-08-2016 y 05-08-2016), sobre normas preceptuadas en los artículos $4^{\circ}$ bis, ter, quáter y quinquis del Código Tributario. 
determinado contribuyente. El cambio en el tratamiento tributario de las diferencias surgidas en fusiones propias e impropias impide al contribuyente reconocer las pérdidas reflejadas en un Goodwill sino hasta el momento de la disolución de la sociedad absorbente o bien, al término de giro de la misma.

La inequidad de las mencionadas modificaciones legales puede motivar conductas no deseadas en el contribuyente al pretender la búsqueda de la anhelada justicia tributaria cuando intenta, en una legítima razón de negocio, reorganizar sus operaciones empresariales en la búsqueda de la eficiencia de sus actividades. Más aún si consideramos que las nuevas normas impositivas anti elusión contempladas en el Código Tributario serán - según entendidos en esta materia - de difícil aplicabilidad y que las sanciones surgidas por infracciones reveladas en las facultades de tasación del ente fiscalizador, no contemplan la aplicación de las normas del artículo $21^{\circ}$ de la LIR, precepto que considera impuestos de control, sino que se considerarán como resultados del ejercicio en que se produce la fusión, y por consiguiente, se afectarán con el Impuesto de Primera Categoría correspondiente a ese ejercicio.

Las recomendaciones planteadas en el presente artículo permitirían acceder al legítimo derecho de los contribuyentes de reconocer pérdidas generadas en sus actividades. Si las restricciones que motivaron la reforma de 2014 surgieron de las abultadas utilidades alcanzadas por importantes AFPs, la respuesta normativa debería haber considerado los efectos negativos que podria ocasionar a muchos otros contribuyentes.

\section{- Referencias}

Centro de Conocimientos Tributarios. (2017) Centro de Conocimientos Tributarios. Recuperado de http:// www.cctchile.com/.

Código Tributario. (1974). Código Tributario. Santiago. Chile. "Editorial"

Flores, G. y Vergara, G. (2014). Desafíos en Tiempos de Reformas Tributarias:
Fundamentos, objetivos y control. Santiago. Chile. Legal Publishing.

Pinto Perry, G. (2006). Fusión de Empresas. Santiago. Chile. LexisNexis.

Ley N824. Diario Oficial de la República de Chile. Santiago. Chile. 31 de diciembre de 1974
Ley N830. Diario Oficial de la República de Chile. Santiago. Chile. 31 de diciembre de 1974 .

Ley $N^{\circ} 20.630$, Diario Oficial de la República de Chile. Santiago. Chile. 27 de septiembre de 2012.

Ley $N^{\circ} 20.780$. Diario Oficial de la República de Chile. Santiago. Chile. 29 de septiembre de 2014
Ley sobre Impuesto a la Renta. Diario Oficial de la República. Santiago. Chile. 08 febrero de 2016.

Servicio de Impuesto Interno. (2014). Circular N¹3. Recuperado de www. ssi.cl.

Servicio de Impuesto Interno. (2014). Circular No1. Recuperado de www.sii.cl.

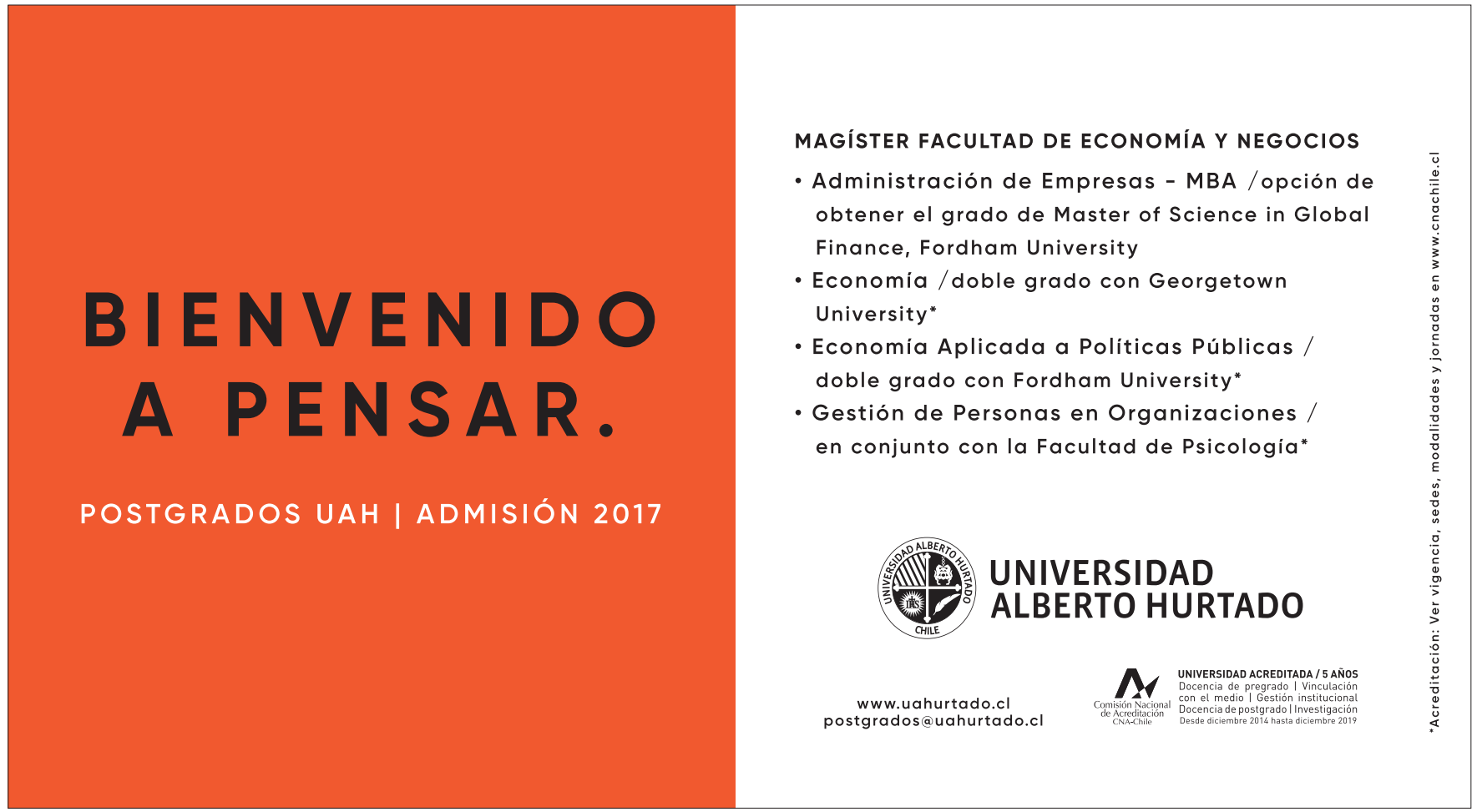

